\title{
Predictive Factors for Radiation Pneumonitis in Patients Receiving Intensity-modulated Radiation Therapy for Thoracic Malignancy
}

\author{
Aleks Sorra E II ${ }^{*}$, Thomas Schroeder ${ }^{1}$, Ben Liem¹, William Thompson ${ }^{1}$ and Sagus Sampath ${ }^{2}$ \\ ${ }^{1}$ University of New Mexico Cancer Center, $1^{\text {st }}$ University of New Mexico, 1201 Camino de Salud NE, Albuquerque, NM 87131-0001, USA \\ ${ }^{2}$ City of Hope National Medical Center, 1500 East Duarte Road, Duarte, CA 91010, USA
}

\begin{abstract}
Purpose: It is unknown whether established dose-volume parameters predictive of radiation pneumonitis (RP) are applicable to multiple disease sites. We investigated the factors associated with RP in a heterogeneous population of patients receiving thoracic radiation.

Methods and materials: Ninety-nine patients who received thoracic radiation with helical tomotherapy were included in this retrospective chart review. Correlation studies were performed and significant clinical and dosimetric factors predictive for grade $\geq 3 \mathrm{RP}$ were assessed using Cox multivariate analysis (MVA).

Results: Fifty-two patients developed RP (grade 1-5), the majority having grade 1 toxicity. Five patients experienced grade $\geq 3$ RP. Eleven patients developed $\geq 2$ RP. The mean time to RP was 3 months. The sole predictor of RP on MVA was a lung volume receiving a maximum of 20 Gy (VS20) $<1600$ cc's (hazard ratio=14.7, $p<0.01$ ). The percentage of lung receiving $\geq 5$ Gy or $\geq 20$ Gy were not significant predictors for RP. The grade $\geq 3$ RP-free survival at 1 year in patients with a VS20 <1600 cc's versus $\geq 1600$ cc's was $50.0 \%$ and $97.1 \%$, respectively (logrank, $p<0.01$ ). Results were similar when the RP threshold was lowered to include grade $\geq 2$.
\end{abstract}

Conclusions: A VS20 <1600 cc's is a significant adverse factor associated with RP; this included cases that were RP grade $\geq 3$ and $\geq 2$. This is a new dosimetric parameter that can be utilized for treatment planning.

Keywords: Radiation pneumonitis; Radiotherapy; Volume spared; Dose-Volume histogram; Lung dose; IMRT

\section{Introduction}

Radiation pneumonitis (RP) is one of the potential adverse effects of thoracic radiation therapy (TRT). Clinical symptoms include dyspnea, fever and non-productive cough, accompanied by pulmonary infiltrates on imaging studies. Non-specific radiographic changes such as patchy or diffuse opacification, nodular infiltrates and air bronchograms can be appreciated [1,2]. A review by Rodriguez et al. [3] reported that 13$37 \%$ of patients treated with RT for lung cancer developed RP.

A multitude of dose-volume histogram (DVH) and tumor parameters have been studied as possible predictors for RP in order to minimize the incidence of this treatment-associated complication. These include the percentage of lung volume receiving a certain radiation dose or higher $(\mathrm{Vx})$, the absolute volume of lung receiving less than a certain maximum dose (volume spared or VSx), the mean lung dose (MLD), the minimum dose to $35 \%$ of the lung volume $\left(\mathrm{D}_{35}\right)$, the normal tissue complication probability (NTCP), and tumor location [1,3-13].

The majority of published data comes from patients receiving TRT for lung cancer. Multiple DVH metrics have been proposed, including the V5 [11,13], V10 [10], V13 [10], V20 [5,14], V25 [15], V30 $[4,9]$ and MLD [14]. Each of these factors has been heralded to carry prognostic significance for RP. Wang et al. demonstrated that the VS5 was a robust factor in patients receiving pre-operative chemo-radiation for esophageal cancer [12]. Whether these parameters are clinically applicable to other disease sites involving the thorax is a subject of ongoing debate. In addition, the applicability of these data to patients treated with intensity-modulated radiation therapy (IMRT) is also questionable, given that patients from these studies were largely treated using conventional three-dimensional treatment planning approaches.

The argued benefit of using IMRT to treat tumors of the thorax is the increased ability to spare critical organs in the radiation field that have tolerances generally less the target prescription dose. These include the spinal cord, heart, esophagus, and lung. However, there is also concern that lower radiation doses spread out over larger volumes of normal lung tissue may be harmful [16]. Helical tomotherapy (HT) uses an IMRT technique of beam entry from 360 degrees delivered in a spiral fashion, which can yield highly conformal dose distributions over conventional IMRT planning [17]. However, the achievement of steep dose gradients comes at the cost of increasing the amount of normal lung volume receiving a lower dose. This may be associated with an increased risk for RP, as reported by Song et al. [17].

At our institution, we have been accumulating clinical experience with HT in treating a variety of malignancies centered in the thoracic region. In a heterogeneous patient cohort, we conducted a retrospective analysis to test the hypothesis that volumes of lower lung dose are not predictive for RP across a broad range of tumor sites. We also sought to identify novel clinical and dosimetric factors prognostic for RP in our treated population.

\section{Methods}

An initial query generated a list of patients receiving radiation at

*Corresponding author: Aleks Sorra E, University of New Mexico Cancer Center 1st University of New Mexico, 1201 Camino de Salud NE Albuquerque, NM 87131-0001, USA, Tel: 505-350-9963; E-mail: esorra@salud.unm.edu

Received January 20, 2013; Accepted April 18, 2013; Published April 20, 2013

Citation: Aleks Sorra E II, Schroeder T, Liem B, Thompson W, Sampath S (2013) Predictive Factors for Radiation Pneumonitis in Patients Receiving Intensitymodulated Radiation Therapy for Thoracic Malignancy. J Nucl Med Radiat Ther 4 149. doi:10.4172/2155-9619.1000149

Copyright: ( 2013 Aleks Sorra E II, et al. This is an open-access article distributed under the terms of the Creative Commons Attribution License, which permits unrestricted use, distribution, and reproduction in any medium, provided the original author and source are credited. 
our institution on the Tomotherapy linear accelerator from 2007 to the present. Patients were included on study if the majority of the thorax (measured in a cranial-caudal dimension) was in the radiated field. A total radiation dose greater than $30 \mathrm{~Gy}$ was required for eligibility. Patients were excluded if they had less than 6 months of follow-up after completion of therapy without a documented RP event.

Our institutional review board approved this retrospective study. Patient and tumor information were gathered by electronic chart review and entered into a secure database. DVH data was obtained from the electronic treatment planning records if available or from the hard copy located in the patient's chart.

$\mathrm{RP}$ was scored according to the Common Terminology Criteria for Adverse Events (CTCAE) Version 4.0, which can be found in table 1. An RP grade $\geq 3$ was defined as a clinically significant event and was used for all primary statistical analyses. Subsequent analyses were used to include RP as defined by grade $\geq 2$ and are specified as such. RP-free survival was calculated based on the start date of RT to either the date of last follow up note, date of death, or the first date that RP was noted in the medical record.

The following factors were included in the analysis: Total lung V5-35 in 5 Gy increments (in percentage), total lung VS5-35 in 5 Gy increments (units of cubic centimeters [cc's]), MLD, total lung volume (TLV), chronic obstructive pulmonary disease (COPD) status (no or yes), smoking history (none or yes), pack-years smoking, gender, race, age, primary tumor type, and whether concurrent chemotherapy was given (no or yes). TLV was defined as the total lung tissue minus the gross tumor volume.

\section{Statistical methods}

Statistical analysis was conducted using SPSS version 20.0 software (SPSS Inc, Chicago, IL). A Pearson correlation test was used to determine whether a relationship existed between the dosimetric variables and the development of RP. Two-tailed $t$-testing was performed to determine whether there was a significant difference in the mean dosimetric parameters between RP and non-RP groups. Multivariate analysis was conducted using a Cox proportional hazards $[18,19]$. Lung DVH parameters were initially inputted as continuous variables. These parameters were also coded as categorical variables based on pre-determined thresholds. Kaplan-Meier analyses were performed to identify differences in RP-free survival as a function of dosimetric variables [20].

\section{Results}

A total of 99 patients were included in this study. Their characteristics are listed in table 2 . The majority of the cases were NSCLC (51\%). Eleven patients had esophageal cancer. A total of 52 patients developed RP (grade 1-5) with $41 \%$ having grade 1 toxicity. Five patients had grade $\geq 3 \mathrm{RP}$ and eleven patients had grade $\geq 2 \mathrm{RP}$.

Table 3 lists the demographic, tumor, and DVH information for the six patients who developed grade $\geq 3$ RP. RP was diagnosed within 2-4 months of receiving radiation therapy. Two of the five patients are alive at time of last follow-up. One had a primary NSCLC and received definitive chemo-radiation. One patient had grade 5 RP. Case 3 had a stage IV T-cell lymphoblastic leukemia with a bulky mediastinal mass. The patient completed hyper-CVAD (cytoxan, vincristine, adriamycin, and dexamethasone) chemotherapy along with intrathecal methotrexate approximately 1 month prior to starting thoracic radiation. Three weeks after radiation treatment, the patient developed fevers, shortness of breath, and increased oxygen requirement, which resulted in hospital admission. CT scanning demonstrated diffuse bilateral pulmonary infiltrates. Sputum and blood cultures were negative, and there was no improvement with broad-spectrum antibiotics or high-dose steroids. The patient remained ventilator-dependent and care was ultimately withdrawn with family consent.

Case 1 received concurrent topotecan on an institutional clinical trial, with 2 other patients on that trial developing RP who were not treated with HT (unpublished data). The remaining patients in table 3 included one with adenocarcinoma of the gastro-esophageal junction treated with definitive chemo-radiation. One had a recurrent breast cancer who received HT to her chest wall and mediastinum.

All of the VSx variables, except for VS30, and the TLV were found to have significant correlation with grade $\geq 3 \mathrm{RP}$ (Table 4). The V5V35, VS30 and MLD did not correlate with the development of RP (data not shown).

There were significant differences in the VS5-VS35 and TLV between the non-RP and $\geq 3 \mathrm{RP}$ groups (Table 5). The difference in the mean TLV was $1090 \mathrm{cc}$ 's, which achieved statistical significance $(t=2.193, p=0.031)$. No significant differences in the mean V5-V35 and MLD were observed between the two groups. This table also includes differences between non-RP and $\geq 2 \mathrm{RP}$ which were more heterogeneous groups as shown by less intergroup variation.

Table 6 displays the results of the Cox regression analysis. Model 1 included all patients $(n=99)$, with the VS20 categorical factor ( $<$ versus $\geq$ $1600 \mathrm{cc}$ 's) being the only significant covariate $(\mathrm{p}<0.01)$. The group with $<1600$ cc's carried a hazard ratio (HR) of 14.76 with a $95 \%$ confidence interval of $2.46-88.48$. Age, sex, the use of concurrent chemotherapy, smoking status, COPD, cancer type, and race were not significant predictors in the model. Model 2 comprised of non-lung cancer patients, and VS20 remained the only variable with significance. No model was achievable when assessing only the lung cancer population. When coded as continuous variables, none of the DVH parameters, including the V5-V35 or VS5-35, reached significance in the models. When the data set was expanded to include $\geq 2$ RP patients, the VS20 categorical factor (<versus $\geq 1600 \mathrm{cc}$ 's) was still the only significant covariate $(\mathrm{p}<0.01)$.

There was a statistically significant difference in the RP-free survival between patients with a lung VS20 $<1600 \mathrm{cc}$ versus $\geq 1600 \mathrm{cc}$ with a 1 year-actuarial estimate of $55.0 \%$ and $97.1 \%$, respectively (log-

\begin{tabular}{|l|l|}
\hline Pneumonitis Grade & Definition \\
\hline 1 & Asymptomatic; clinical or diagnostic observations only; intervention not indicated \\
\hline 2 & Symptomatic; medical intervention indicated; limiting instrumental ADL \\
\hline 3 & Severe symptoms; limiting self care ADL; oxygen indicated \\
\hline 4 & Life-threatening respiratory compromise; urgent intervention indicated (e.g., tracheotomy or intubation) \\
\hline 5 & Death \\
\hline
\end{tabular}

Abbreviations: ADL: Activity of Daily Living

Table 1: Common Terminology Criteria for Adverse Events (CTCAE) Version 4.0 grading scale for pneumonitis. 
Citation: Aleks Sorra E II, Schroeder T, Liem B, Thompson W, Sampath S (2013) Predictive Factors for Radiation Pneumonitis in Patients Receiving Intensity-modulated Radiation Therapy for Thoracic Malignancy. J Nucl Med Radiat Ther 4: 149. doi:10.4172/2155-9619.1000149

Page 3 of 6

\begin{tabular}{|c|c|c|c|}
\hline Characteristic & $\mathrm{N}=99$ & & Number (\%) \\
\hline Age & Average Age & $63(17-88)$ & \\
\hline \multirow{2}{*}{ Sex } & Male & 56 & $57 \%$ \\
\hline & Female & 43 & $43 \%$ \\
\hline \multirow{2}{*}{ History of smoking } & Yes & 75 & $76 \%$ \\
\hline & No & 24 & $24 \%$ \\
\hline \multirow{5}{*}{ Race } & White & 54 & $55 \%$ \\
\hline & Hispanic & 22 & $22 \%$ \\
\hline & Native American & 4 & $4 \%$ \\
\hline & African American & 3 & $3 \%$ \\
\hline & Other/Unknown & 16 & $16 \%$ \\
\hline \multirow{3}{*}{ COPD: } & Yes & 26 & $26 \%$ \\
\hline & No & 61 & $62 \%$ \\
\hline & Unknown & 12 & $12 \%$ \\
\hline \multirow{5}{*}{ Cancer type } & Non-small cell lung & 50 & $51 \%$ \\
\hline & Esophagus & 11 & $11 \%$ \\
\hline & Small Cell lung & 6 & $6 \%$ \\
\hline & Other & 22 & $22 \%$ \\
\hline & Metastases to lung & 10 & $10 \%$ \\
\hline \multirow{5}{*}{ Chemotherapy } & None & 30 & $30 \%$ \\
\hline & Neoadjuvant & 9 & $9 \%$ \\
\hline & Concurrent & 47 & $47 \%$ \\
\hline & Previous (unspecified) & 10 & $10 \%$ \\
\hline & Unknown & 3 & $3 \%$ \\
\hline \multirow{6}{*}{ Clinical RP Grade } & 0 & 47 & $47 \%$ \\
\hline & 1 & 41 & $41 \%$ \\
\hline & 2 & 6 & $6 \%$ \\
\hline & 3 & 3 & $3 \%$ \\
\hline & 4 & 1 & $1 \%$ \\
\hline & 5 & 1 & $1 \%$ \\
\hline Mean Lung Dose & $9.68 \mathrm{~Gy}$ & & \\
\hline Mean Total Lung Volume & $3290 \mathrm{cc}$ & & \\
\hline
\end{tabular}

Abbreviations: COPD: Chronic Obstructive Pulmonary Disease; RP: Radiation Pneumonitis; CC: Cubic Centimeter

Table 2: Patient Characteristics.

\begin{tabular}{|c|c|c|c|c|c|}
\hline Patient Information & Case 1 & Case 2 & Case 3 & Case 4 & Case 5 \\
\hline Age & 54 & 52 & 50 & 57 & 51 \\
\hline Sex & Male & Female & Male & Female & Male \\
\hline Pack Years & 0 & 0 & 0 & 0 & Did smoke, unknown time \\
\hline Race & White & Unkno wn & Hispanic & Hispanic & White \\
\hline V5 (\%) & $77 \%$ & $43 \%$ & $99 \%$ & $50 \%$ & $60 \%$ \\
\hline V10 (\%) & $44 \%$ & $19 \%$ & $93 \%$ & $6 \%$ & $48 \%$ \\
\hline V15 (\%) & $23 \%$ & $8 \%$ & $70 \%$ & $2 \%$ & $22 \%$ \\
\hline V20 (\%) & $18 \%$ & $1 \%$ & $35 \%$ & $0 \%$ & $10 \%$ \\
\hline V25 (\%) & $15 \%$ & $0 \%$ & $24 \%$ & $0 \%$ & $6 \%$ \\
\hline V30 (\%) & $12 \%$ & $0 \%$ & $15 \%$ & $0 \%$ & $4 \%$ \\
\hline V35 (\%) & $9 \%$ & $0 \%$ & $5 \%$ & $0 \%$ & $3 \%$ \\
\hline VS5 (cc's) & 660.42 & 741 & 17.78 & 786.48 & 1496.77 \\
\hline VS10 (cc's) & 1606.35 & 1050.62 & 124.45 & 1547.79 & 1964.51 \\
\hline VS15 (cc's) & 2220.63 & 1187.94 & 533.35 & 1572.96 & 2933.67 \\
\hline VS20 (cc's) & 2370.59 & 1278.62 & 1155.58 & 1572.96 & 3367.74 \\
\hline VS25 (cc's) & 2457.11 & 1295.46 & 1351.14 & 1572.96 & 3517.41 \\
\hline VS30 (cc's) & 2537.86 & 1295.46 & 1520.04 & 1572.96 & 3592.25 \\
\hline VS35 (cc's) & 2621.49 & 1295.46 & 1688.93 & 1572.96 & 3648.38 \\
\hline MLD (gy) & 13.3 & 5.4 & 19.58 & 5.34 & 9.88 \\
\hline TLV (cc's) & 2883.93 & 1295.46 & 1777.82 & 1572.96 & 3741.93 \\
\hline COPD & No & No & No & Unknown & Unknown \\
\hline $\begin{array}{l}\text { Concurrent chemotherapy, } \\
\text { type }\end{array}$ & $\begin{array}{l}\text { Yes, } \\
\text { Topotecan }\end{array}$ & No & No & No & Yes, Taxotere/cisplatin \\
\hline Cancer Type & NSCLC & Breast & $\begin{array}{l}\text { Lymphoblastic Lymphoma with } \\
\text { mediastinal metastasis }\end{array}$ & $\begin{array}{c}\text { Carcinosarcoma of the } \\
\text { lung }\end{array}$ & $\begin{array}{l}\text { Adenocarcinoma of gastro-esophageal } \\
\text { junction }\end{array}$ \\
\hline Total Dose (Gy) & 63 & 50 & 36 & 60 & 50.4 \\
\hline Months To RP & 2.17 & 3.12 & 4.27 & 3.55 & 2.35 \\
\hline Survival Status & Alive & Deceased & Deceased & Deceased & Alive \\
\hline RP Grade & 3 & 4 & 5 & 3 & 3 \\
\hline
\end{tabular}

Abbreviations: Vx: Percentage of lung receiving at least X Gy; VSx: Volume of lung spared X Gy or higher; MLD: Mean Lung Dose; TLV: Total Lung Volume; COPD: Chronic Obstructive Pulmonary Disease; RP: Radiation Pneumonitis; CC's: Cubic Centimeter; NSCLC: Non-Small Cell Lung Cancer

Table 3: Characteristics of grade $\geq 3$ RP cases. 
Citation: Aleks Sorra E II, Schroeder T, Liem B, Thompson W, Sampath S (2013) Predictive Factors for Radiation Pneumonitis in Patients Receiving Intensity-modulated Radiation Therapy for Thoracic Malignancy. J Nucl Med Radiat Ther 4: 149. doi:10.4172/2155-9619.1000149

Page 4 of 6

\begin{tabular}{|c|c|c|c|c|c|c|c|c|c|c|}
\hline$n=99$ & & VS5 & VS10 & VS15 & VS20 & VS25 & VS30 & VS35 & MLD & TLV \\
\hline RP Grade $>=3$ & Pearson Correlation & -0.206 & -0.204 & -0.208 & -0.206 & -0.211 & -0.197 & -0.209 & 0.052 & -0.217 \\
\hline & Significance. (2-tailed) & $0.040^{*}$ & $0.043^{*}$ & $0.039^{*}$ & $0.042^{*}$ & $0.036^{*}$ & 0.05 & $0.038^{*}$ & 0.651 & $0.012^{*}$ \\
\hline
\end{tabular}

Abbreviations: VSx: Volume of lung spared X Gy; MLD: Mean Lung Dose; TLV: Total Lung Volume; RP: Radiation Pneumonitis; ${ }^{*}$ p-value statistically significant at < 0.05

Table 4: Correlation of Dose-volume histogram (DVH) data with RP grade $\geq 3$.

\begin{tabular}{|c|c|c|c|c|c|}
\hline & Non-RP mean & $\mathrm{RP} \geq 3$ mean & Sig. (2-tailed) & $\mathrm{RP} \geq 2$ mean & Sig. (2-tailed) \\
\hline & $n=94$ & $n=5$ & & $n=11$ & \\
\hline V5 (\%) & $50 \%$ & $66 \%$ & 0.171 & $64 \%$ & 0.055 \\
\hline V10 (\%) & $34 \%$ & $42 \%$ & 0.415 & $44 \%$ & 0.123 \\
\hline V15 (\%) & $21 \%$ & $25 \%$ & 0.593 & $27 \%$ & 0.18 \\
\hline V20 (\%) & $14 \%$ & $13 \%$ & 0.815 & $17 \%$ & 0.251 \\
\hline V25 (\%) & $10 \%$ & $9 \%$ & 0.768 & $12 \%$ & 0.188 \\
\hline V30 (\%) & $7 \%$ & $6 \%$ & 0.602 & $9 \%$ & 0.263 \\
\hline V35 (\%) & $5 \%$ & $3 \%$ & 0.279 & $6 \%$ & 0.591 \\
\hline VS5 (cc's) & 1704 & 740 & $0.040^{*}$ & 1082 & $0.049^{*}$ \\
\hline VS10 (cc's) & 2232 & 1258 & $0.043^{*}$ & 1599 & $0.05^{*}$ \\
\hline VS15 (cc's) & 2642 & 1689 & $0.039^{*}$ & 2068 & 0.066 \\
\hline VS20 (cc's) & 2890 & 1949 & $0.041^{*}$ & 2350 & 0.084 \\
\hline VS25 (cc's) & 3019 & 2038 & $0.036^{*}$ & 2470 & 0.086 \\
\hline VS30 (cc's) & 3074 & 2103 & 0.05 & 2559 & 0.13 \\
\hline VS35 (cc's) & 3161 & 2165 & $0.038^{*}$ & 2631 & 0.108 \\
\hline MLD (Gy) & 9.6 & 10.7 & 0.615 & 11.7 & 0.127 \\
\hline TCLV (cc's) & 3344 & 2254 & $0.031^{*}$ & 2798 & 0.117 \\
\hline
\end{tabular}

Abbreviations: RP: Radiation pneumonitis; Vx: Percentage of lung receiving at least X Gy; VSx: Volume of lung spared X Gy; MLD: Mean Lung Dose; TLV: Total Lung Volume; CC's: Cubic Centimeter; * $p$-value statistically significant at $<0.05$

Table 5: Comparison of Means of Dosimetric Variables.

\begin{tabular}{|c|c|c|c|c|}
\hline & & Significance & HR & $95.0 \% \mathrm{Cl}$ \\
\hline Model $1, \mathrm{n}=99$ & VS20 <1600cc's (vs. $\geq 1600$ cc's) & 0.003 & 14.762 & $2.46-88.48$ \\
\hline Model $2, n=43$ & TLV < 2000cc's (vs $\geq 2000 c c ' s$ ) & 0.015 & 16.565 & $1.719-159.641$ \\
\hline Model 3, n=99 & VS20 <1600cc's (vs. $\geq 1600$ cc's) & 0.005 & 5.731 & $1.676-19.596$ \\
\hline
\end{tabular}

Abbreviations: VSx: Volume of lung spared X Gy or higher; CC's: Cubic Centimeters; HR: Hazard Ratio; Cl: Confidence Interval

Table 6: Multivariate analysis: Cox Models

rank, $\mathrm{p}<0.01$, Figure 1). Again, when we expanded the data to include $\geq 2 \mathrm{RP}$ patients, the same relationship held true with a 1 year-actuarial estimate of $50.0 \%$ and $96.6 \%$, respectively (log-rank, $\mathrm{p}<0.01$ ) (Figure 2 ).

\section{Discussion}

There are multiple DVH parameters that have been reported as significant predictors for RP, which has made it challenging for the clinician at the time of treatment planning. In general, it is intuitive that lowering the amount of radiation dose to the lung will reduce the risk for RP. However, the question of partial-lung tolerance and whether the lung is more sensitive to lower doses versus higher doses remains unanswered. In addition, it is unknown whether such parameters apply only to lung cancer patients, or whether these values apply to a broader population who receive thoracic radiation. In this analysis of patients with various disease sites treated with HT, we show that sparing 1600 $\mathrm{cc}$ or more of lung from receiving a maximum of $20 \mathrm{~Gy}$ is associated with a lower risk of developing RP. This is the first study to report this specific dosimetric variable as a significant factor.

The sentinel paper from Graham et al. [5] reported that the volume (in percentage) of total lung receiving 20 Gy or higher (V20) was a significant variable in NSCLC patients receiving RT alone. The significant parameter in our study, the VS20, is the converse of the V20, and therefore their respective values are tied to each other. From one perspective, our findings agree with the Graham analysis, in that both studies acknowledge the clinical importance of the 20 Gy threshold for normal lung tissue. However, when testing the V20 in our MVA, it failed to reach statistical significance. The MD Anderson group reported that the V20 of the remaining intact lung was the sole predictor for pulmonary-related death in mesothelioma patients receiving post-operative IMRT [21]. Similarly, in patients with NSCLC receiving concurrent chemotherapy, the ipsilateral V20 and V30 were found to confer additional predictive value for RP when fulfilling established DVH constraints for total lung [22]. We are unable to comment on the significance of the ipsilateral VS20 in our study-set because this data was not available. Additional studies are needed to see if the VSx is superior to the $\mathrm{Vx}$ in predicting for RP in NSCLC.

Over a broader range of disease sites, the volume-spared metric (VSx) threshold, specifically the VS20, may be a more robust predictor for RP than traditional Vx percentage values. When including only the non-lung cancer patients in model 2 of our MVA, the VS20 persisted as a significant factor associated with RP. In our analysis, none of the Vx variables (using both continuous and categorical values) were found to be predictive in the multivariate model. The VSx may provide more detailed information regarding the functional capacity of lung to tolerate a certain dose, and therefore correlate better with clinical symptoms. For example, a V20 of $20 \%$ in a patient with 3000 $\mathrm{cc}$ total lung volume might be tolerable, but this may not be the case in a patient with only a $2000 \mathrm{cc}$ lung volume. This also supports the 


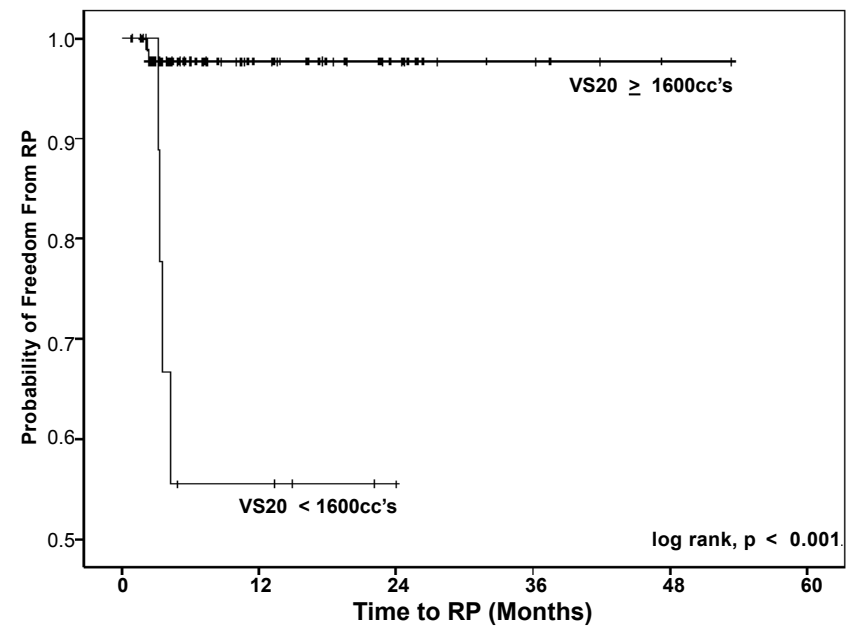

Abbreviations: RP: radiation pneumonitis, VSx: Volume of lung spared X Gy, CC's: Cubic centimeters.

Figure 1: Kaplan-Meier analysis. Freedom from grade $\geq 3$ pneumonitis postradiation treatment as a function of the total lung VS20 < or $\geq 1600 \mathrm{cc}$ 's.

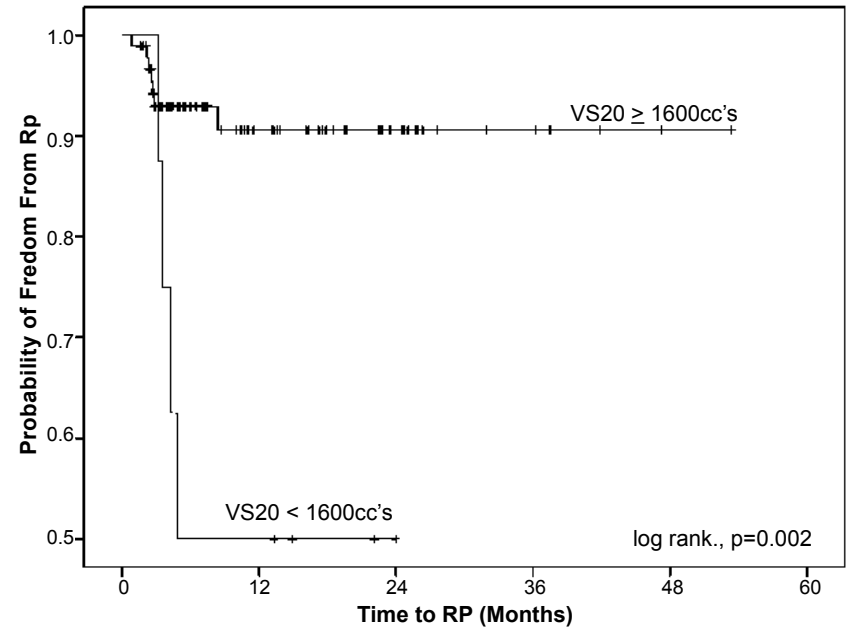

Abbreviations: RP: radiation pneumonitis, VSx: Volume of lung spared X Gy, CC's: Cubic centimeters

Figure 2: Kaplan-Meier analysis. Freedom from grade $\geq 2$ pneumonitis postradiation treatment as a function of the total lung VS20 < or $\geq 1600 \mathrm{cc}$ 's.

idea of the lung being a "parallel" organ of functional subunits (FSUs), where a minimum number of FSU's are needed in order for the organ to function without incurring irreparable toxicity.

Our findings do not support the assertion that the risk of RP is related to larger lung volumes receiving lower doses such as $5 \mathrm{~Gy}$. This is in opposition to an analysis by Song et al. [18] who reported the contralateral lung V5 as the only significant predictor in their MVA of 37 NSCLC patients receiving HT. Wang et al. [12] reported on a volume-spared variable, the VS5 as the most important predictor for $\mathrm{RP}$ in esophageal patients receiving pre-operative chemo-radiation. Yom et al. [13] in their series of NSCLC patients receiving combined modality therapy with IMRT, reported that a lung V5 value of $>70 \%$ was predictive for RP. The mesothelioma literature also supports the potential value of limiting the V5, as reported by Komaki et al. [23]. We attempted to generate a multivariate model that included only the patients with lung cancer. This was not achievable, likely attributable to a paucity of events along with small sample size. When including all the patients, we found the VS5 to be a significant discriminator in terms of RP-free survival on univariate analysis (results not shown), but it did not reach significance in the MVA. This provides intriguing evidence that the harm of lower lung dose to large volumes may only apply to lung cancer and/or those patients undergoing thoracic surgery in conjunction with radiation. We recommend that caution be exercised before using the V5 or VS5 to evaluate treatment plans for other clinical scenarios.

Both the VSx and Vx values are impacted by the TLV, as higher total lung volumes will have larger volumes of lung spared a certain dose, and also increase the denominator in the Vx calculation. On MVA the TLV was not a significant factor. However, there was a significant difference in the mean TLV between the patients who experienced grade $\geq 3 \mathrm{RP}$ and those who did not. When the MVA was repeated to include grade $\geq 2 \mathrm{RP}$ cases as well, the results were still statistically significant. This adds reassurance to the validity of the results since the non-RP and grade $\geq 2 \mathrm{RP}$ groups were not statistically different in their TLV or VS20 values.

To our knowledge, the impact of this specific parameter has not been addressed in the literature. Reasons for this may be the multiple confounding factors that can influence the TLV. In our series, patients did not have a uniform method of respiration at time of CT simulation. It is possible that image acquisition at the time of end-expiration may have yielded a falsely lower TLV. Nevertheless, 3 of the 5 patients with grade 3 or higher RP had a TLV of $<2000 \mathrm{cc}$. We recommend this metric be assessed in larger studies.

The V5, V10, V15, and VS15 were less robust prognostic factors compared to the VS20, as these were only significant on univariate analysis (data not shown). This is concordant with prior studies showing association of RP with V10 and V5 $[5,10]$ as well as VS5 [12].

Multiple studies have shown MLD to be a significantly associated with RP $[3,4,7,21,23]$. Our study, in contrast, did not find a relationship between post-therapy pulmonary complications and MLD.

It is interesting that of the five cases of grade 3 or higher RP, 4 were non-smokers and 3 out of 5 did not have COPD. This is aligned with studies indicating that smokers might actually have a lower chance of developing RP than non-smokers [6,24]. Differentiating between a severe COPD exacerbation and RP can be very difficult, and continues to be a confounder in analyses, including the present study $[25,26]$. Although studies have shown that patients with COPD can have worsening pulmonary function tests after radiation compared to their non-COPD counterparts, this might not increase their chances for developing RP [27].

This study is subject to multiple criticisms appropriate of a retrospective report. Despite established CTCAE criteria, the grading of RP is known to be inconsistent across studies [28]. This has continued to fuel ongoing skepticism and controversy regarding the relationship of dose-volume data to RP. Another possible limitation to our study is smaller sample size and RP events. With reduced number of events, our statistical outcomes may not be as robust as larger studies. The heterogeneous patient population can be perceived as suboptimal, as similar DVH studies used patients with a single disease site 
Citation: Aleks Sorra E II, Schroeder T, Liem B, Thompson W, Sampath S (2013) Predictive Factors for Radiation Pneumonitis in Patients Receiving Intensity-modulated Radiation Therapy for Thoracic Malignancy. J Nucl Med Radiat Ther 4: 149. doi:10.4172/2155-9619.1000149

and uniform treatment. We consider this to be a unique strength of our study, as our results may be applicable to a larger base of patients, not just those with lung or esophageal cancer. Lung DVH factors may influence the development of RP regardless of disease site, especially in those patients receiving IMRT.

\section{Conclusion}

In this analysis we show that a VS20 $<1600$ cc's was a significant adverse prognostic factor for the development of clinically significant $\mathrm{RP}$ in patients receiving thoracic radiation with $\mathrm{HT}$.

\section{References}

1. Hope AJ, Lindsay PE, El Naqa I, Alaly JR, Vicic M, et al. (2006) Modeling radiation pneumonitis risk with clinical, dosimetric, and spatial parameters. Int $\mathrm{J}$ Radiat Oncol Biol Phys 65: 112-124

2. Park HJ, Kim KJ, Park SH, Kay CS, Oh JS (2009) Early CT findings of tomotherapy-induced radiation pneumonitis after treatment of lung malignancy. AJR Am J Roentgenol 193: W209-213.

3. Rodrigues G, Lock M, D'Souza D, Yu E, Van Dyk J (2004) Prediction of radiation pneumonitis by dose - volume histogram parameters in lung cancer-a systematic review. Radiother Oncol 71: 127-138.

4. Fay M, Tan A, Fisher R, Mac Manus M, Wirth A, et al. (2005) Dose-volume histogram analysis as predictor of radiation pneumonitis in primary lung cancer patients treated with radiotherapy. Int J Radiat Oncol Biol Phys 61: 1355-1363.

5. Graham MV, Purdy JA, Emami B, Harms W, Bosch W, et al. (1999) Clinical dose-volume histogram analysis for pneumonitis after 3D treatment for nonsmall cell lung cancer (NSCLC) Int J Radiat Oncol Biol Phys 45: 323-329.

6. Hernando ML, Marks LB, Bentel GC, Zhou SM, Hollis D, et al. (2001) Radiationinduced pulmonary toxicity: a dose-volume histogram analysis in 201 patients with lung cancer. Int J Radiat Oncol Biol Phys 51: 650-659.

7. Kwa SL, Lebesque JV, Theuws JC, Marks LB, Munley MT, et al. (1998) Radiation pneumonitis as a function of mean lung dose: an analysis of pooled data of 540 patients. Int J Radiat Oncol Biol Phys 42: 1-9.

8. Marks LB, Munley MT, Bentel GC, Zhou SM, Hollis D, et al. (1997) Physical and biological predictors of changes in whole-lung function following thoracic irradiation. Int J Radiat Oncol Biol Phys 39: 563-570.

9. Piotrowski T, Matecka-Nowak M, Milecki P (2005) Prediction of radiation pneumonitis: dose-volume histogram analysis in 62 patients with non-small cell lung cancer after three-dimensional conformal radiotherapy. Neoplasma 52: 56-62.

10. Schallenkamp JM, Miller RC, Brinkmann DH, Foote T, Garces YI (2007) Incidence of radiation pneumonitis after thoracic irradiation: Dose-volume correlates. Int J Radiat Oncol Biol Phys 67: 410-416.

11. Wang S, Liao Z, Wei X, Liu HH, Tucker SL, et al. (2006) Analysis of Clinical and Dosimetric Factors Associated with Treatment-Related Pneumonitis (Trp) in Patients with Non-Small-Cell Lung Cancer (Nsclc) Treated with Concurrent Chemotherapy and Three-Dimensional Conformal Radiotherapy (3d-Crt). Int $\mathrm{J}$ Radiat Oncol Biol Phys 66: 1399-1407.

12. Wang SL, Liao Z, Vaporciyan AA, Tucker SL, Liu H, et al. (2006) Investigation of clinical and dosimetric factors associated with postoperative pulmonary complications in esophageal cancer patients treated with concurrent chemoradiotherapy followed by surgery. Int J Radiat Oncol Biol Phys 64: 692699 .

13. Yom SS, Liao Z, Liu HH, Tucker SL, Hu CS, et al. (2007) Initial evaluation of treatment-related pneumonitis in advanced-stage non-small-cell lung cancer patients treated with concurrent chemotherapy and intensity-modulated radiotherapy. Int J Radiat Oncol Biol Phys 68: 94-102.

14. Barriger RB, Forquer JA, Brabham JG, Andolino DL, Shapiro RH, et al. (2012)
A dose-volume analysis of radiation pneumonitis in non-small cell lung cancer patients treated with stereotactic body radiation therapy. Int J Radiat Oncol Biol Phys 82: 457-462.

15. Matsuo Y, Shibuya K, Nakamura M, Narabayashi M, Sakanaka K, et al. (2012) Dose--volume metrics associated with radiation pneumonitis after stereotactic body radiation therapy for lung cancer. Int J Radiat Oncol Biol Phys 83: e545549.

16. Gopal R, Tucker SL, Komaki R, Liao Z, Forster KM, et al. (2003) The relationship between local dose and loss of function for irradiated lung. Int $\mathrm{J}$ Radiat Oncol Biol Phys 56: 106-113.

17. Song WY, Huh SN, Liang Y, White G, Nichols RC, et al. (2010) Dosimetric comparison study between intensity modulated radiation therapy and threedimensional conformal proton therapy for pelvic bone marrow sparing in the treatment of cervical cancer. J Appl Clin Med Phys 11: 3255.

18. Song CH, Pyo H, Moon SH, Kim TH, Kim DW, et al. (2010) Treatment-related pneumonitis and acute esophagitis in non-small-cell lung cancer patients treated with chemotherapy and helical tomotherapy. Int J Radiat Oncol Biol Phys 78: 651-658.

19. Cox D (1972) Regression Model and Life Tables. J R Stat Soc 34: 187-220.

20. El Kaplan PM (1958) Nonparametric Estimation from Incomplete Observations Journal of the American Statistical Association 53: 457-481.

21. Rice DC, Smythe WR, Liao Z, Guerrero T, Chang JY, et al. (2007) Dosedependent pulmonary toxicity after postoperative intensity-modulated radiotherapy for malignant pleural mesothelioma. Int J Radiat Oncol Biol Phys 69: $350-357$

22. Ramella S, Trodella L, Mineo TC, Pompeo E, Stimato G, et al. (2010) Adding ipsilateral $\mathrm{V} 20$ and $\mathrm{V} 30$ to conventional dosimetric constraints predicts radiation pneumonitis in stage IIIA-B NSCLC treated with combined-modality therapy. In J Radiat Oncol Biol Phys 76: 110-115.

23. Komaki R, Liao Z, Liu H, Tucker S, Rice D (2006) Fatal Pneumonitis Associated with Intensity-Modulated Radiation Therapy for Mesothelioma. Int J Radiat Oncol Biol Phys 65: 640-645.

24. Takeda A, Kunieda E, Ohashi T, Aoki Y, Oku Y, et al. (2012) Severe COPD is correlated with mild radiation pneumonitis following stereotactic body radiotherapy. Chest 141: $858-866$.

25. Yirmibesoglu E, Higginson DS, Fayda M, Rivera MP, Halle J, et al. (2012) Challenges scoring radiation pneumonitis in patients irradiated for lung cancer Lung Cancer 76: 350-353.

26. Kocak Z, Evans ES, Zhou SM, Miller KL, Folz RJ, et al. (2005) Challenges in defining radiation pneumonitis in patients with lung cancer. Int $J$ Radiat Oncol Biol Phys 62: 635-638.

27. Borst GR, De Jaeger K, Belderbos JS, Burgers SA, Lebesque JV (2005) Pulmonary function changes after radiotherapy in non-small-cell lung cancer patients with long-term disease-free survival. Int J Radiat Oncol Biol Phys 62: 639-644.

28. Lopez Guerra JL, Gomez D, Zhuang Y, Levy LB, Eapen G, et al. (2012) Change in diffusing capacity after radiation as an objective measure for grading radiation pneumonitis in patients treated for non-small-cell lung cancer. Int $J$ Radiat Oncol Biol Phys 83: 1573-1579. 